\title{
ELABORAÇÃO E CARACTERIZAÇÃO DE BEBIDAS À BASE DE EXTRATO HIDROSSOLÚVEL DE SOJA COM POLPA DE PITANGA, AMORA E MIRTILO
}

\author{
Marcos Bertani Gazola1 \\ Deyse Pegorini² \\ Vanderlei Aparecido de Lima ${ }^{3}$ \\ Roberta Roncatti ${ }^{4}$ \\ Sirlei Dias Teixeira ${ }^{5}$ \\ Edimir Andrade Pereira ${ }^{6}$
}

\begin{abstract}
Atualmente, observa-se uma busca do consumidor por alimentos com elevadas propriedades nutricionais e funcionais, despertando o interesse das agroindústrias por frutas com características exóticas. Este trabalho tem como objetivo o desenvolvimento de bebidas a base de soja nos sabores pitanga, amora e mirtilo. A caracterização das polpas e da bebida foi feita através de análises físico-químicas e microbiológicas, além da aplicação de análise sensorial no produto desenvolvido. Entre as análises físico-químicas de conteúdo mineral, proteínas, sólidos, lipídios e glicídios, o pH foi o descritor que melhor explicou a diferença entre as polpas e as bebidas (Análise de Componentes Principais - ACP). Na realização da análise sensorial das bebidas o índice de aceitação foi satisfatório, indicando potencial para a industrialização das mesmas e necessidade de maior intensificação do aroma e sabor no desenvolvimento do produto final.
\end{abstract}

PALAVRAS-CHAVE: POLPAS DE FRUTAS, FLORESTA COM ARAUCÁRIA, CARACTERIZAÇÃO FÍSICO-QUÍMICA E MICROBIOLÓGICA, ANÁLISE SENSORIAL.

1 Mestrando em Tecnologia de Processos Químicos e Bioquímicos. Universidade Tecnológica Federal do Paraná, Câmpus Pato Branco. E-mail: marcosb.g@ibest.com.br

2 Acadêmica do curso de Química da UTFPR, Câmpus Pato Branco. Universidade Tecnológica Federal do Paraná, Câmpus Pato Branco. E-mail: deysepegorini@hotmail.com

3 Doutor em Engenharia Química. Professor do curso de Química da UTFPR, Câmpus Pato Branco. Universidade Tecnológica Federal do Paraná, Câmpus Pato Branco. E-mail: valima66@gmail.com

4 Mestranda em Tecnologia de Processos Químicos e Bioquímicos. Universidade Tecnológica Federal do Paraná, Câmpus Pato Branco. E-mail: roberta-roncatti@hotmail.com

5 Doutora em Química Orgânica, Produtos Naturais e Ecologia Química, Professora do Programa de Pós Graduação em Tecnologia de Processos Químicos e Bioquímicos, e do curso de Química da UTFPR, Câmpus Pato Branco. Universidade Tecnológica Federal do Paraná, Câmpus Pato Branco. E-mail: sirlei@utfpr.edu.br

6 Doutor em Ciências em Tecnologia Processos Químicos e Bioquímicos, Professor do Programa de Pós Graduação em Tecnologia de Processos Químicos e Bioquímicos, e do curso de Química da UTFPR, Câmpus Pato Branco. Universidade Tecnológica Federal do Paraná, Câmpus Pato Branco. E-mail: edimir@utfpr.edu.br 


\section{INTRODUÇÃO}

O Brasil apresenta grande diversidade de clima, solo e vegetação, tornando-o apto para o cultivo de diversas espécies vegetais, incluindo frutíferos de origem nativa ou exótica.

As frutas são alimentos de grande valor nutricional e devem estar presentes diariamente na dieta. Elas são fontes de água, vitaminas, sais minerais, fibras e compostos bioativos. O Brasil ocupa a terceira colocação no ranking da produção mundial de frutas e é responsável por $5,7 \%$ do volume colhido, com uma produção de 41,5 milhões de toneladas (SEAB, 2012).

A soja é considerada um alimento funcional devido suas características químicas e nutricionais. Houve uma grande expansão na produção desta leguminosa, cuja safra em 2013, segundo Conab (2013), atingiu 81.456,7 milhões de toneladas (22,7\% superior a 2012).

Visando o aumento do valor nutricional da alimentação humana, diversos produtos derivados da soja podem ser empregados, destacando-se seu extrato hidrossolúvel por apresentar baixo custo de produção, alto valor nutritivo e obtenção facilitada (FELBERG et al., 2004), consistindo em um dos produtos mais conhecidos dentre os derivados deste grão (POLYCARPO et al., 2012). Este extrato é rico em proteínas, ferro e niacina, não apresenta lactose e colesterol, possui baixo teor de gordura e carboidratos (RODRÍGUEZ-ROQUE et al., 2013). Entretanto o consumo de soja na dieta ocidental ainda é baixo devido principalmente ao gosto residual deste grão decorrente de compostos voláteis produzidos durante a desintegração do mesmo com água (BRANCO et al., 2007). Com a inclusão de polpa de frutas e tecnologias empregadas no processamento que reduzem as características sensoriais indesejáveis, o consumo tem aumentando na última década, diversificando os sabores dos produtos disponíveis no mercado.

Em face da necessidade de desenvolvimento de bebidas alternativas às de base láctea, destacam-se as importantes contribuições de bebidas a base de soja para dieta, aliada à procura do consumidor por produtos mais saudáveis e seguros. O produto desenvolvido inova ao trazer uma abordagem mercadológica diferenciada das tradicionais bebidas, com o objetivo de promover 0 sabor de frutas nativas, como pitanga, provenientes dos remanescentes da Floresta com Araucária; e frutas raras e exóticas como a amora e o mirtilo, utilizando-as como matérias-primas em formulações com alto valor nutricional.

A pitanga (Eugenia uniflora L.) é nativa do Brasil (CELLI; PEREIRA-NETTO; BETA, 2011), apresentando sabor exótico e agradável (OLIVEIRA et al., 2006). A amora comum é uma espécie nativa da Ásia, (OZRENK et al., 2010), e o mirtilo de várias regiões da Europa e da América do Norte, sendo recentemente introduzido no Brasil (SARKIS et al., 2013), onde é pouco conhecido e estudado (FACHINELLO, 2008).

Diante destes fatos, este estudo teve como objetivo desenvolver bebidas à base de soja e frutas nativas e exóticas do sudoeste do Paraná, e realizar a caracterização físico-química, microbiológica e sensorial do produto.

\section{MATERIAL E MÉTODOS}

\subsection{MATÉRIA-PRIMA}

Os frutos nativos da Floresta com Araucária de pitanga e exóticos de amora tiveram aquisição feita de forma extrativista no município de Vitorino e os frutos de mirtilo foram adquiridos de cultivo comercial no município de Palmas, região sudoeste do estado do Paraná.

$\mathrm{Na}$ formulação das bebidas foram utilizados: pectina Genu ${ }^{\circledR}$ tipo YM 115-H fabricada pela CP Kelko (lote LI 23057) e extrato de soja em pó (marca Jasmine ${ }^{\circledR}$, lote 121106), e açúcar granulado cristalizado, adquirido no comércio local. 


\subsection{PROCESSAMENTO DOS FRUTAS}

Os frutos foram recebidos e classificados quanto a seus atributos de qualidade (cor, uniformidade, grau de maturação, isenção de doenças, etc.), sendo então lavados em água potável, higienizados (solução com 250 ppm de cloro, por 15 minutos), enxaguados (lavagem com imersão em água para retirada do excesso de cloro), drenados e despolpados utilizando liquidificador comercial da marca Black\&Decker $\AA$ modelo LE700-BR (para amora e mirtilo) e processador de alimentos da marca Fun Kitchen modelo HR-800 (para pitanga). Posterormente foram acondicionados em sacos plásticos transparentes de polietileno de baixa densidade e congelamento em freezer doméstico (aproximadamente $-18{ }^{\circ} \mathrm{C}$ ), até o momento de seu uso na caracterização e/ou formulação das bebidas.

\subsection{DESENVOLVIMENTO DAS BEBIDAS A BASE DE SOJA}

Durante o desenvolvimento da formulação, foram realizados uma série de experimentos prévios, levando-se em conta o ponto de equilíbrio entre os seus componentes e também os parâmetros grau de doçura, acidez, aroma e sabor. A bebida selecionada através destes testes sensoriais com a equipe formada por professores, mestrando e bolsistas de Iniciação Científica foi novamente formulada, optando-se pela que apresentou melhor resultado (não separação de fases). Foram preparadas três bebidas, uma para cada polpa de fruta, contendo pectina, polpa de fruta, açúcar e extrato hidrossolúvel de soja em pó reconstituído. As proporções de polpa de fruta e de açúcar forma fixadas em $25 \%$ e $12 \%$, respectivamente, visando padronizar as bebidas formuladas para análise sensorial e demais testes. O teor de pectina foi determinado após oito pré-testes, variando de $0,0 \%$ a $1,6 \%$, atingindo-se o ideal em $0,2 \%$. Para melhorar o aspecto visual do produto, as polpas foram filtradas em tecido musseline, para remoção de resíduos sólidos, acarretando em maior homogeneidade das bebidas.

\subsection{ANÁLISES FÍSICO-QUÍMICAS}

A caracterização físico-química das polpas in natura e das bebidas ocorreu através das determinações de umidade, $\mathrm{pH}$, acidez titulável total, proteínas, lipídios, glicídios totais em glicose, sólidos totais, sólidos solúveis totais, sólidos insolúveis totais e cinzas, baseando-se nos métodos do Instituto Adolfo Lutz (ZENEBON et al., 2008). O teor de carboidratos totais foi determinado por diferença. Todas as análises foram realizadas em duplicata.

\subsection{ANÁLISES MICROBIOLÓGICAS}

Nas polpas in natura foi realizada pesquisa de Coliformes termotolerantes a $45^{\circ} \mathrm{C}$, bolores e leveduras, e teste de presença/ausência para Salmonella $s p$ de acordo com metodologias apresentadas na Instrução Normativa $n^{\circ}$ 62/2003 do Ministério da Agricultura, Pecuária e Abastecimento (BRASIL, 2003). Nas bebidas, além destes micro-organismos foram determinados os teores de Bacillus cereus, através da ISO 7932 (ISO, 2005).

\subsection{ANÁLISE SENSORIAL}

Visando verificar a aceitação das bebidas formuladas, 80 provadores não treinados participaram da análise sensorial mediante teste afetivo, utilizando escala hedônica com nove pontos, para os atributos aparência, aroma, sabor, viscosidade e impressão global, conforme recomendado pela NBR 14141/98 (ABNT 1998) e utilizado por Rivaldi et al. (2009). Foi realizado teste de intenção de compra do provador, com cinco pontos. A frequência de consumo de bebidas à base de soja também foi pesquisada, baseando-se em Dutcosky (2007). Posteriormente foi determinado, o índice de aceitabilidade (IA) das bebidas (OLIVEIRA et al., 2013). Cada provador 
recebeu três amostras codificadas aleatoriamente (bebidas à base de soja, sabor pitanga - 185, amora - 346, e mirtilo - 724) refrigeradas a aproximadamente $7^{\circ} \mathrm{C}$, dispostas em recipientes plástico de cor branca de $50 \mathrm{~mL}$, identificados. Água mineral à temperatura ambiente foi disponibilizada para efetuar a limpeza do palato, entre as amostras. O experimento foi conduzido no refeitório da Universidade Tecnológica Federal do Paraná, câmpus Pato Branco, após testes microbiológicos que garantiram a segurança alimentar dos julgadores, e também após aprovação por Comitê de Ética em Pesquisa da Universidade Tecnológica Federal do Paraná (parecer oㅜ 243.217).

\subsection{ANÁLISE ESTATÍSTICA}

O conjunto de dados correspondentes às variáveis dependentes foi submetido à análise de homogeneidade de variância pelo teste de Cochran C e de normalidade pelo teste de ShapiroWilk. As variáveis que apresentaram homocedasticidade entre suas variâncias foram submetidas à análise de variância (ANOVA) e ao teste de Tukey ao nível de 5\% de significância. Nos resultados da caracterização físico-química das polpas e das bebidas foram realizadas, também, análises estatísticas multivariadas: análise de agrupamento e de componentes principais (ACP), cujos dados foram previamente normalizados através da função "Standardize" do software utilizado (Statistica ${ }^{\circledR}$ 8.0).

\section{RESULTADOS E DISCUSSÃO}

Fatores climáticos, genéticos e as características do solo influenciam na composição de frutos, tornando sua caracterização físico-química fundamental em função da região de plantio e manejo. Diante disto, os resultados da caracterização físico-química das polpas estão mostrados na Tabela 1, enquanto que das bebidas a base de soja, situam-se na Tabela 2.

\section{TABELA 1 - CARACTERÍSTICAS FÍSICO-QUÍMICAS DAS POLPAS DE PITANGA, AMORA E MIRTILO}

Parâmetro Polpa de pitanga Polpa de amora Polpa de mirtilo

\begin{tabular}{lccc}
\hline Umidade (\%) & $85,06^{\mathrm{a}} \pm 0,05$ & $90,21^{\mathrm{b}} \pm 0,16$ & $81,87^{\mathrm{c}} \pm 0,07$ \\
$\mathrm{pH}$ & $3,72^{\mathrm{a}} \pm 0,16$ & $3,79^{\mathrm{a}} \pm 0,16$ & $2,86^{\mathrm{b}} \pm 0,07$ \\
Acidez titulável total (mg L-1 EAC) & $1,25^{\mathrm{a}} \pm 0,01$ & $1,41^{\mathrm{b}} \pm 0,01^{*}$ & $1,04^{\mathrm{c}} \pm 0,01$ \\
Proteínas (\%) & $1,62^{\mathrm{a}} \pm 0,10$ & $1,10^{\mathrm{b}} \pm 0,09$ & $0,51^{\mathrm{c}} \pm 0,01$ \\
Lipídios (\%) & $0,33^{\mathrm{a}} \pm 0,03$ & $0,47^{\mathrm{b}} \pm 0,01$ & $0,40^{\mathrm{a}, \mathrm{b}} \pm 0,01$ \\
Glicídios totais em glicose (\%) & $12,35^{\mathrm{a}} \pm 0,05$ & $10,29^{\mathrm{b}} \pm 0,05$ & $10,40^{\mathrm{b}} \pm 0,03$ \\
Sólidos totais (\%) & $14,94^{\mathrm{a}} \pm 0,05$ & $9,79^{\mathrm{b}} \pm 0,16$ & $18,13^{\mathrm{c}} \pm 0,07$ \\
Sólidos solúveis totais ( ${ }^{\circ}$ Brix) & $12,05^{\mathrm{a}} \pm 0,07$ & $6,05^{\mathrm{b}} \pm 0,07$ & $14,05^{\mathrm{c}} \pm 0,07$ \\
Sólidos insolúveis totais (\%) & $3,15^{\mathrm{a}, \mathrm{b}} \pm 0,07$ & $2,80^{\mathrm{a}} \pm 0,14$ & $3,35^{\mathrm{b}} \pm 0,07$ \\
Cinzas (\%) & $0,90^{\mathrm{a}} \pm 0,02$ & $0,95^{\mathrm{a}} \pm 0,03$ & $0,97^{\mathrm{a}} \pm 0,01$ \\
Carboidratos totais (\%) & $12,09^{\mathrm{a}} \pm 0,15$ & $7,28^{\mathrm{b}} \pm 0,29$ & $16,26^{\mathrm{c}} \pm 0,05$ \\
\hline
\end{tabular}

Notas: média \pm desvio padrão; EAC: equivalente ácido cítrico; * $\mathrm{mg} \mathrm{L}^{-1}$ equivalente ácido málico; médias seguidas por letras iguais na linha não diferem entre si estatisticamente pelo Teste de Tukey ( $\square \square 0,05)$. 
TABELA 2 - CARACTERÍSTICAS FÍSICO-QUÍMICAS DAS BEBIDAS

\begin{tabular}{lccc}
\hline \multicolumn{1}{c}{ Parâmetro } & BPI & BAM & BMI \\
\hline Umidade (\%) & $82,95^{\mathrm{a}} \pm 0,01$ & $83,79^{\mathrm{b}} \pm 0,04$ & $85,59^{\mathrm{c}} \pm 0,03$ \\
$\mathrm{pH}$ & $4,30^{\mathrm{a}} \pm 0,29$ & $4,22^{\mathrm{a}} \pm 0,31$ & $3,46^{\mathrm{a}} \pm 0,22$ \\
Acidez titulável total (mg L ${ }^{-1}$ EAC) & $0,63^{\mathrm{a}} \pm 0,01$ & $0,71^{\mathrm{b}} \pm 0,01^{*}$ & $0,65^{\mathrm{a}} \pm 0,01$ \\
Proteínas (\%) & $0,80^{\mathrm{a}} \pm 0,08$ & $0,88^{\mathrm{a}} \pm 0,01$ & $0,72^{\mathrm{a}} \pm 0,03$ \\
Lipídios (\%) & $0,21^{\mathrm{a}} \pm 0,02$ & $0,22^{\mathrm{a}} \pm 0,03$ & $0,23^{\mathrm{a}} \pm 0,01$ \\
Glicídios totais em glicose (\%) & $3,92^{\mathrm{a}} \pm 0,06$ & $4,60^{\mathrm{b}} \pm 0,04$ & $4,10^{\mathrm{c}} \pm 0,03$ \\
Sólidos totais (\%) & $17,05^{\mathrm{a}} \pm 0,01$ & $16,21^{\mathrm{b}} \pm 0,04$ & $14,41^{\mathrm{c}} \pm 0,01$ \\
Sólidos solúveis totais ( ${ }^{\circ}$ Brix) & $15,05^{\mathrm{a}} \pm 0,07$ & $11,45^{\mathrm{b}} \pm 0,07$ & $16,05^{\mathrm{c}} \pm 0,07$ \\
Sólidos insolúveis totais (\%) & $1,75^{\mathrm{a}} \pm 0,07$ & $1,35^{\mathrm{b}} \pm 0,07$ & $1,55^{\mathrm{a}, \mathrm{b}} \pm 0,07$ \\
Cinzas (\%) & $0,84^{\mathrm{a}} \pm 0,04$ & $0,77^{\mathrm{a}} \pm 0,01$ & $0,79^{\mathrm{a}} \pm 0,01$ \\
Carboidratos totais $(\%)$ & $15,22^{\mathrm{a}} \pm 0,15$ & $14,34^{\mathrm{b}} \pm 0,01$ & $12,68^{\mathrm{c}} \pm 0,05$ \\
\hline
\end{tabular}

Notas: média \pm desvio padrão; EAC: equivalente ácido cítrico; * $\mathrm{mg} \mathrm{L}^{-1}$ equivalente ácido málico; BPI: Bebida sabor pitanga; BAM: Bebida sabor amora; BMI: Bebida sabor mirtilo; SS: sólidos solúveis totais; ATT: acidez titulável total; médias seguidas por letras iguais na linha não diferem entre si pelo Teste de Tukey $(p \square 0,05)$.

A análise de agrupamento foi realizada com todo o conjunto de dados das polpas de frutas e de suas respectivas bebidas a base de soja. O dendrograma relativo às polpas e bebidas encontra-se representado na Figura 1, onde se constata que há homocedasticidade entre os dados, agrupando polpas de frutas, separando-as de suas bebidas. Verifica-se a formação de quatro grupos (distância vinculada com nível de corte entre 1,98 e 3,99, determinado por Amalgamation Schedule), sendo que a polpa de mirtilo é a mais homogênea entre si (menor distância vinculada).

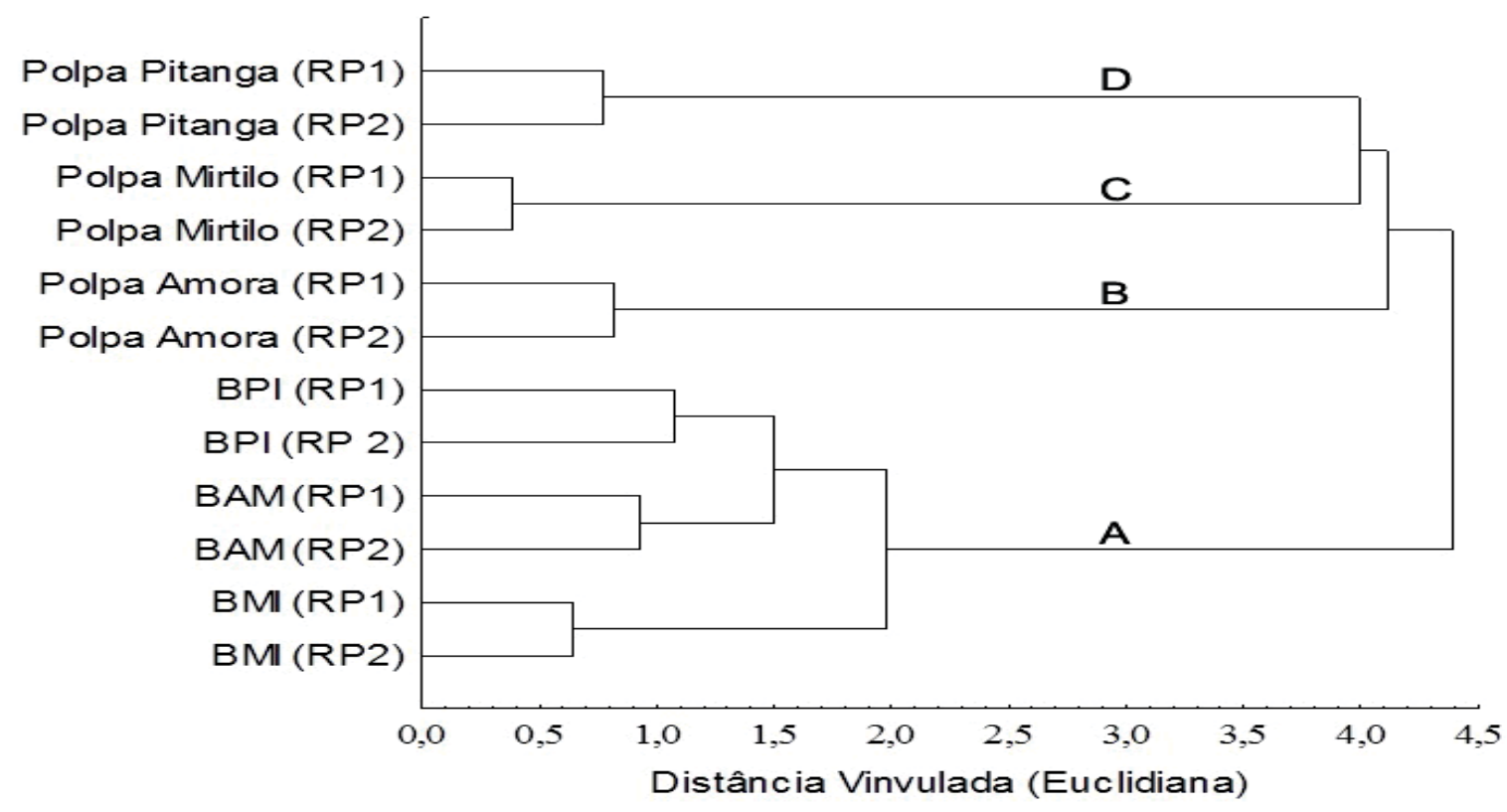

FIGURA 1 - DENDOGRAMA PARA AS POLPAS E AS BEBIDAS MISTAS

BPI: bebida de pitanga: BAM: bebida de amora; BMI: bebida de mirtilo; RP1: replicata 1; RP2: replicata 2 
Com o intuito de verificar quais descritores explicam melhor a diferença na caracterização físico-química entre as polpas e as bebidas, aplicou-se a análise de componentes principais (ACP), representada na Figura 1.

Neste caso, dois componentes explicaram $83,98 \%$ da variabilidade dos dados. Observando a Figura 2, verifica-se que as polpas de pitanga, amora e mirtilo foram separadas em grupos próprios (D, B, C, respectivamente), por apresentarem características que as diferenciam das outras polpas e bebidas, sendo que estas formam um único grupo $(A)$.

A CP1 separa o grupo das bebidas dos das polpas, enquanto que a CP2 distingue a polpa de pitanga e mirtilo da polpa de amora e das bebidas.

A análise estatística multivariada revela que o descritor que melhor explica a diferença entre o grupo A dos demais é o $\mathrm{pH}$, cujo valor nas polpas variou de 2,86 a 3,79, enquanto que nas bebidas, oscilou de 3,46 na BMI a 4,30 na BPI. O caráter ácido é característica importante que desfavorece o desenvolvimento de micro-organismos bacterianos. Ercisli; Orhan (2008) encontraram pH entre 3,43 e 3,66 para cinco genótipos de amora, enquanto que Moraes et al. (2007) verificaram entre 2,56 a 2,67 em amostra de mirtilo. Em relação às bebidas, Vieira; Silva; Glória (2010) observaram, em suco concentrado de laranja, $\mathrm{pH}$ de 3,72 , e, em três formulações de néctar de banana, o pH variou de 4,49 a 4,59 (MESQUITA et al., 2009).
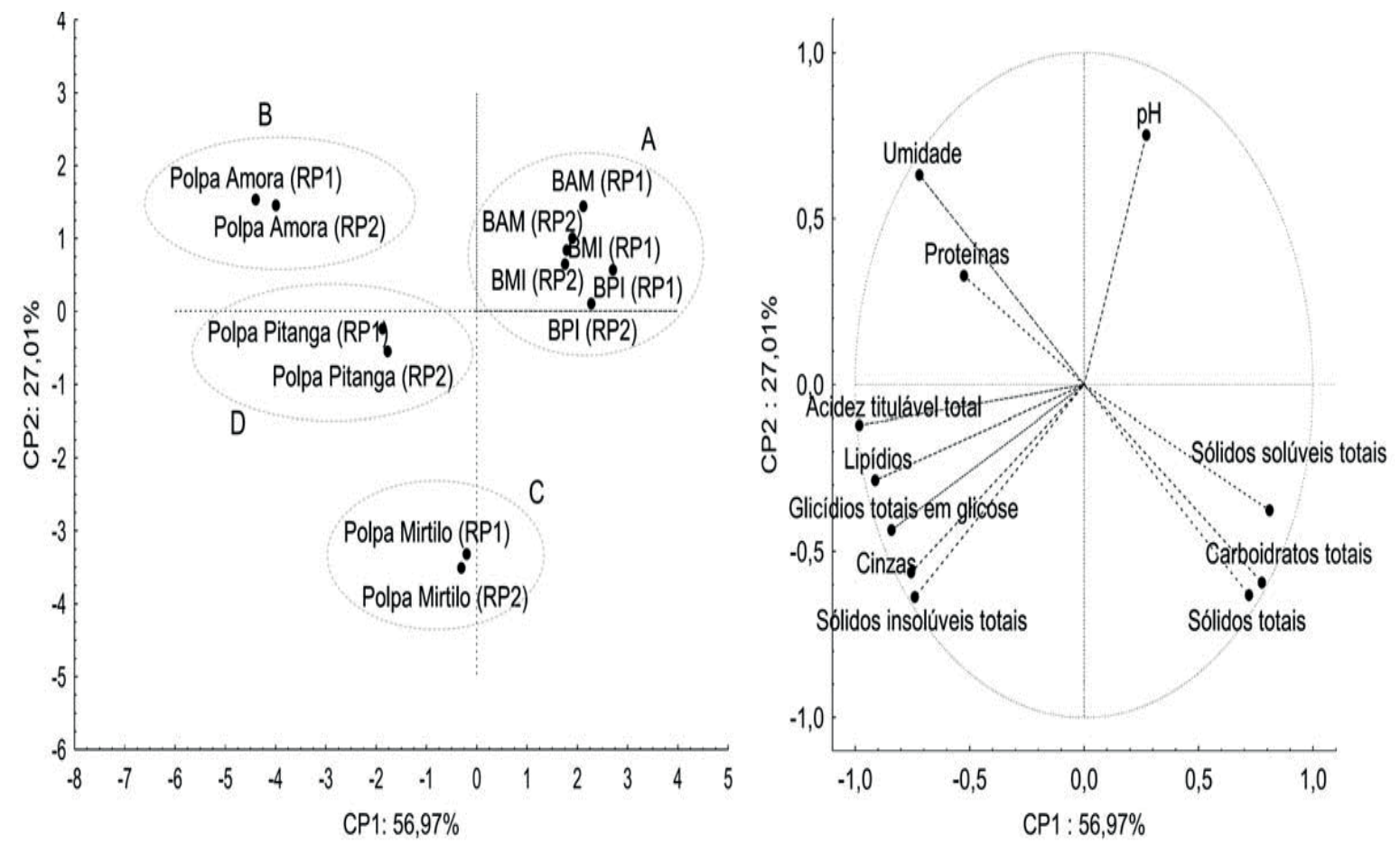

\section{FIGURA 2 - PROJEÇÃO DOS CASOS NO PLANO FATORIAL 1,2 E CÍRCULO DE CORRELAÇÃO (VARIÁVEIS) DAS POLPAS E BEBIDAS}

RP1: replicata 1; RP2: replicata 2; CP1: componente principal 1; CP2: componente principal 2

Sólidos solúveis totais, sólidos totais e carboidratos totais com autovetores positivos, e umidade, proteínas, acidez titulável total, lipídios, glicídios totais em glicose, sólidos insolúveis totais e cinzas com autovetores negativos, comandam o eixo da CP1. Já o eixo da CP2 é altamente influenciado pelos autovetores positivos de umidade e $\mathrm{pH}$, e negativos de sólidos totais, sólidos insolúveis totais, cinzas e carboidratos totais.

Devido a alta umidade dos frutos, a industrialização na forma de polpa congelada garante sua conservação e comercialização. A polpa de amora se destaca pelos seus altos teores de 
umidade $(90,21 \%)$ e proteínas $(1,10 \%)$, sendo este inferior somente ao da polpa de pitanga $(1,62 \%)$ que ficou próximo a Bagetti et al. (2011) em pitanga vermelha (1,4\%). A umidade é superior aos $82,40 \%$ e $72,60 \%$, verificados por Imran et al. (2010) e Ercisli; Orhan (2007), respectivamente. A polpa de mirtilo que apresentou a menor umidade $(81,87 \%)$, sendo similar a Mercali et al. (2011), que encontraram $82,16 \%$. Em relação às bebidas, a umidade foi mais evidente na BMI $(85,59 \%)$. Uliana; Venturini Filho (2010) verificaram $89 \%$ em bebida de soja e amora (10 ${ }^{\circ}$ Brix) na proporção 1:1 de EHS:suco de amora.

Antônio et al. (2009) obteve $0,52 \%$ de proteínas em amostra de mirtilo, similar ao observado na Tabela 2. O teor de proteínas das bebidas verificado entre $0,72 \%$ a $0,88 \%$ é superior aos de Bezerra et al. (2013) que obteve $0,28 \%$ de proteína em suco misto de acerola, maracujá e taperebá, devido à presença de soja nas bebidas e nos frutos.

A polpa de pitanga é influenciada pelos teores de acidez titulável total, lipídios, glicídios totais em glicose, cinzas e sólidos insolúveis totais (Figura 2).

A acidez titulável total apresentou maior valor para a polpa de amora e menor teor para a polpa de mirtilo. Lopes; Mattietto; Menezes (2005), verificou o teor de 1,24 g $100 \mathrm{~g}^{-1}$ para polpa de pitanga. A BAM demonstrou a maior acidez titulável total do grupo $A$, sendo inferior a suco de amora preta (Rubus spp.), 1,24 a 1,50 $\mathrm{mg} \mathrm{L}^{-1}$ equivalente ácido cítrico (MOTA, 2006).

A maioria das frutas apresenta baixo teor de lipídios, sendo o menor teor deste $(0,21 \%)$ encontrado na BPI e o maior na polpa de amora $(0,47 \%)$. Resultados similares para as polpas de pitanga $(0,40 \%)$ e amora $(0,55 \%)$ foram constatados por Bagetti et al. (2011) e Imran et al. (2010), respectivamente. Contudo, Moraes et al. (2007) obteve variação de $0,25 \%$ a $0,28 \%$. Caus et al. (2008) encontrou de $0,62 \%$ a $1,13 \%$ em bebidas mistas de morango e maracujá.

Os glicídios totais em glicose foram mais evidentes na polpa de pitanga $(12,35 \%)$. Lopes; Mattietto; Menezes (2005) obtiveram 7,77\% de glicídios em pitanga. O resultado determinado neste estudo para a polpa de mirtilo $(10,40 \%)$ se aproxima do teor $(10,67 \%)$ observado por Antonio et al. (2009). O teor mínimo de glicose foi verificado na BPI (3,92\%), sendo superior ao encontrado por Santos et al. (2007) em suco de araçá (0,79\%), porém abaixo de Pinheiro et al. (2006), em seis marcas diferentes de sucos de abacaxi $(6,8 \%$ a 13,3\%). Cabe ressaltar que a quantidade de açúcar presente nas bebidas está diretamente relacionada com a fração correspondente deste ingrediente na composição do produto.

O teor de cinzas foi mais elevado na polpa de mirtilo (0,97\%), superior ao obtido por Antonio et al. (2009), e menos evidente na BMI (0,79\%). Muitas vezes no processo de extração, parte das cinzas não é transferida para o suco, permanecendo no bagaço. Teores inferiores a $1 \%$ em diversos tipos de bebidas, foram observados por Felberg et al. (2004), Caus et al. (2008), Uliana; Venturini Filho (2010) e Bezerra et al. (2013), em bebida mista de soja e castanha, bebida de soja e morango, bebida de soja e amora e suco misto de acerola, respectivamente.

Em relação aos sólidos insolúveis totais, na polpa de pitanga obteve-se 3,15\%, valor intermediário aos das polpas de amora (2,80\%) e de mirtilo (3,35\%).. Contudo, Souza (2008) encontrou $3,36 \%$ e $3,82 \%$, de sólidos insolúveis para amora (Rubus eubatus) e mirtilo. Os sólidos insolúveis totais nas bebidas de pitanga, amora e mirtilo foram $1,75 \%$ e $1,35 \%$ e $1,55 \%$, respectivamente.

A menor porcentagem de sólidos totais foi observada na polpa de amora $(9,79 \%)$, e o maior na polpa de mirtilo (18,13\%). Na polpa de pitanga, os $14,94 \%$ estão acima dos $6,93 \%$ encontrado por Oliveira; Figueirêdo; Queiroz (2006). Na BMI obteve-se 14,41\% de sólidos totais, enquanto que na BAM esta porcentagem foi de $16,21 \%$ e na BPI, de $17,05 \%$. Felberg et al. (2004) verificou $11,46 \%$ de sólidos totais em bebida mista de soja e castanha, enquanto que Rodrigues; Moretti (2008) obtiveram $19,35 \%$ em bebida de soja e polpa de pêssego.

Em relação aos carboidratos totais, o maior valor ocorreu na polpa de mirtilo $(16,26 \%)$ e o menor na polpa de amora $(7,28 \%)$. Tendo em vista que o grupo dos carboidratos inclui, entre outros compostos, glicose, frutose, sacarose, amido, celulose (RIBEIRO; SERAVALLI, 2007), os teores observados nas polpas de pitanga e amora (Tabela 1) não deveriam ser inferiores aos glicídios 
totais em glicose. Porém, esta discrepância pode estar relacionada com a metodologia empregada na determinação dos glicídios totais em glicose, semelhante a de Lane-Eynon que, conforme Silva et al. (2003), podem resultar em valores superestimados de sacarose, pois a hidrólise ácida de açúcares não redutores torna-os redutores no licor de Fehling. Imran et al. (2010) obtiveram 13,83\% de carboidratos totais em polpa de amora, sendo superior ao observado na Tabela 1. Contudo valor similar (16,4\%) ao encontrado para a polpa de mirtilo foi verificado por Moraes et al. (2007).

Nas bebidas, o maior teor de carboidratos totais ocorreu na BPI $(15,22 \%)$ e o menor na BMI $(12,68 \%)$. Conforme esperado, os teores observados nas bebidas são bem superiores aos teores de glicídios totais em glicose, pois, as formulações das bebidas continham 12\% e açúcar. Uliana; Venturini-Filho (2010), observaram $12,50 \%$ de carboidratos totais em bebida mista contendo EHS e suco de amora na proporção 1:2 e $14{ }^{\circ}$ Brix. Caus et al. (2008) obtiveram 15,56\% e 19,25\% em bebidas mistas contento EHS e polpa de morango e de maracujá, respectivamente, ambas com $8 \%$ de açúcar.

O menor teor de sólidos solúveis totais foi detectado na polpa de amora (6,05 $\left.{ }^{\circ} \mathrm{Brix}\right)$, atingindo $16,05^{\circ} \mathrm{Brix}$ na BMI. Entretanto Ercisli; Orhan (2007) obtiveram 16,7 ${ }^{\circ}$ Brix, bem acima do encontrado para a polpa de amora. Abreu et al. (2007) verificou de 9,45 a 15,20 ${ }^{\circ} \mathrm{Brix}$ em sete bebidas mistas de soja.

A relação sólidos solúveis totais/acidez titulável total (SS/ATT) está relacionada ao sabor do fruto, fornecendo o balanço entre o conteúdo de açúcares e de ácidos orgânicos (MEDEIROS et al., 2012), afetando a percepção sensorial. Aroucha et al. (2012), descreve que esta relação é utilizada subjetivamente na avaliação do sabor, sendo desejáveis valores elevados por indicar maior quantidade de açúcares em relação aos ácidos presentes.

Através dos resultados da caracterização microbiológica das polpas (Tabela 3), percebese que todas atendem aos padrões microbiológicos sanitários para alimentos estabelecidos pela legislação vigente, refletindo boas condições higiênico-sanitárias durante o preparo das mesmas. 0 baixo valor de $\mathrm{pH}$ apresentado pelas polpas pode representar um fator limitante para o crescimento de bactérias patogênicas, mantendo os índices de contaminação bacteriana em níveis baixos. Somente na polpa de pitanga houve crescimento de bolores e leveduras $\left(1,0 \times 10^{1}\right.$ UFC $\left.\mathrm{g}^{-1}\right)$. Porém, em quantidade inferior ao padrão estabelecido pela IN n 01/00 (BRASIL, 2000). Esta presença de bolores e leveduras pode estar relacionada com o teor de carboidratos presente e pela acidez da polpa, sendo que baixas concentrações destes microrganismos neste tipo de alimento são consideradas normais (SOUZA; CARNEIRO; GONSALVES, 2011).

TABELA 3 - CARACTERIZAÇÃO MICROBIOLÓGICA DAS POLPAS

\begin{tabular}{lcccc}
\hline \multicolumn{1}{c}{ Parâmetro } & $\begin{array}{c}\text { Polpa de } \\
\text { pitanga }\end{array}$ & $\begin{array}{c}\text { Polpa de } \\
\text { amora }\end{array}$ & $\begin{array}{c}\text { Polpa de } \\
\text { mirtilo }\end{array}$ & Limite legal \\
\hline Bolores e leveduras (UFC g & & & \\
Salmonella sp. $\left(\right.$ presença ou ausência $\left.25 \mathrm{~g}^{-1}\right)$ & ausência & ausência & ausência & ausência** \\
Coliformes a $45^{\circ} \mathrm{C}\left(\mathrm{NMP} \mathrm{g}^{-1}\right)$ & $<3,0 \times 10^{0}$ & $<3,0 \times 10^{0}$ & $<3,0 \times 10^{0}$ & $1,0 \times 10^{2 * *}$ \\
\hline
\end{tabular}

Notas: UFC: Unidade Formadora de Colônia; NMP: Número Mais Provável; *: Brasil (2000); **: Brasil (2001).

Visando segurança alimentar, foi realizada caracterização microbiológica das bebidas (Tabela 4), sendo que todas atenderam aos padrões microbiológicos sanitários para alimentos estabelecidos pela legislação. Nas bebidas de pitanga e mirtilo percebeu-se a presença de bolores 


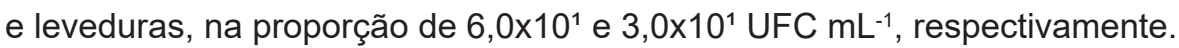

Estudos em outros tipos de bebidas apontam para a presença de bolores e leveduras em

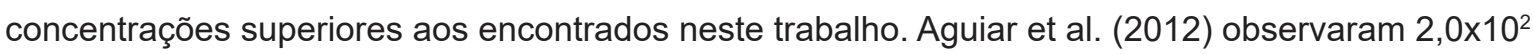
UFC g ${ }^{-1}$ em suco concentrado de maçã através de osmose reversa, enquanto que Mena et al. (2013) verificou $1,41 \times 10^{5} \mathrm{UFC} \mathrm{mL}^{-1}$ em suco de romã.

TABELA 4 - CARACTERIZAÇÃO MICROBIOLÓGICA DAS BEBIDAS

\begin{tabular}{|c|c|c|c|c|}
\hline Parâmetro & BPI & BAM & BMI & $\begin{array}{l}\text { Limite } \\
\text { legal* }\end{array}$ \\
\hline Bolores e leveduras (UFC mL $\mathrm{mL}^{-1}$ ) & $6,0 \times 10^{1}$ & $<1,0 \times 10^{1}$ & $3,0 \times 10^{1}$ & --- \\
\hline Salmonella sp. (presença ou ausência $25 \mathrm{~mL}^{-1}$ ) & aus. & aus. & aus. & aus. \\
\hline Coliformes a $45^{\circ} \mathrm{C}(\mathrm{NMP} \mathrm{mL}-1)$ & $<3,0 \times 10^{0}$ & $<3,0 \times 10^{0}$ & $<3,0 \times 10^{0}$ & $1,0 \times 10^{1}$ \\
\hline Bacillus cereus (UFC mL $\mathrm{mL}^{-1}$ ) & $<1,0 \times 10^{0}$ & $<1,0 \times 10^{0}$ & $<1,0 \times 10^{0}$ & $5,0 \times 10^{2}$ \\
\hline
\end{tabular}

Notas: UFC: Unidade Formadora de Colônia; NMP: Número Mais Provável; *: Brasil (2001); ---: limite legal não encontrado para este tipo de alimento.

Em relação à análise sensorial, a idade média dos provadores foi de 27,5 anos, sendo 46 do gênero feminino e 34 do masculino. Na Tabela 5 são apresentadas as médias e os desvios padrões dos cinco atributos avaliados (aparência, aroma, sabor, viscosidade e impressão global) nas bebidas formuladas.

\section{TABELA 5 - MÉDIAS E DESVIOS PADRÕES DOS ATRIBUTOS DAS BEBIDAS AVALIADAS}

\begin{tabular}{|c|c|c|c|c|c|}
\hline Bebida & Aparência & Aroma & Sabor & Viscosidade & $\begin{array}{c}\text { Impressão } \\
\text { Global }\end{array}$ \\
\hline Pitanga & $6,94^{\mathrm{a}} \pm 1,77$ & $5,94^{\mathrm{a}} \pm 1,66$ & $6,91^{a} \pm 1,73$ & $7,47^{\mathrm{a}} \pm 1,23$ & $7,06^{\mathrm{a}} \pm 1,31$ \\
\hline Amora & $7,20^{\mathrm{a}} \pm 1,51$ & $6,11^{\mathrm{a}} \pm 1,69$ & $6,45^{\mathrm{a}} \pm 2,16$ & $7,29^{\mathrm{a}, \mathrm{b}} \pm 1,61$ & $6,85^{\mathrm{a}} \pm 1,60$ \\
\hline Mirtilo & $6,17^{\mathrm{b}} \pm 1,81$ & $5,90^{\mathrm{a}} \pm 1,68$ & $6,67^{\mathrm{a}} \pm 1,83$ & $6,76^{\mathrm{b}} \pm 1,60$ & $6,75^{a} \pm 1,56$ \\
\hline
\end{tabular}

Através da Tabela 5 percebe-se que a maior nota para ao atributo aparência ocorreu para a bebida de amora, seguida da de pitanga, assim como para o atributo aroma. O sabor, a viscosidade e a impressão global foram melhores pontuados na bebida de pitanga. Contudo não há diferença estatística significativa $(\mathrm{p} £ 0,05)$ para os atributos aroma, sabor e impressão global, sendo que esta aponta para "Gostei regularmente" em todas as amostras.

O índice de aceitabilidade (IA) é apresentado na Tabela 6, assim como o atributo avaliado, a nota média obtida para o atributo e respectiva nota máxima. 
TABELA 6 - ÍNDICE DE ACEITABILIDADE DAS BEBIDAS AVALIADAS

\begin{tabular}{cccccc}
\hline Bebida & Aparência & Aroma & Sabor & Viscosidade & Impressão Global \\
\hline Pitanga & 77,11 & 66,00 & 76,78 & 83,00 & 78,44 \\
Amora & 80,00 & 67,89 & 71,67 & 81,00 & 76,11 \\
Mirtilo & 68,56 & 65,56 & 74,11 & 75,11 & 75,00 \\
\hline
\end{tabular}

Para Bicudo et al. (2012), um produto pode ser considerado aceito quando seu IA é igual ou superior a $70 \%$. Analisando os dados da Tabela 6, percebe-se que o aroma, em todas as bebidas, obteve IA inferior a 70\%, assim como a aparência na bebida de mirtilo. Porém, a impressão global sinaliza para a aceitação dos produtos (IA $>70 \%$ ). O maior valor atingido foi de $83 \%$ na viscosidade da bebida de pitanga.

Estes resultados podem estar relacionado à pouca diversidade de consumo das frutas utilizadas, assim como o paladar próprio de cada indivíduo, não habituado a ingerir frutas com sabor exótico e principalmente o hábito do consumo de derivados de soja.

No Brasil, segundo produtor mundial de soja, o consumo deste alimento ainda é baixo, se comparado com outros países, sendo alguns dos motivos o desconhecimento de seus benefícios nutricionais, sua inserção na alimentação e os produtos disponíveis (MORAIS; SILVA; DAMÁSIO, 2000).

Embora muitas tecnologias tenham obtido êxito na obtenção de extratos com melhores características sensoriais, ainda existe resistência ao consumo, mesmo quando adicionadas a sucos de frutas que conferem melhor sabor e aroma.

Branco et al. (2007) obteve valores abaixo de 7,0 em teste sensorial de bebida a base de soja sabor morango e, constatou, que quanto maior o teor de polpa de morango nas formulações testadas, maior foi a aceitação das bebidas em relação à viscosidade e a cor, sendo que o aumento do teor açúcar, aumentou a nota média do sabor.

Em relação a intenção de compra, não houve diferença estatística pelo teste de Tukey $(p>0,05)$ entre as amostras, indicando que os provadores talvez comprassem os produtos, outra revelação da pesquisa é que o universo de provadores que participaram da análise sensorial são consumidores ocasionais.

Em pesquisa realizada por Behrens; Da Silva (2004), $60 \%$ dos participantes pertenciam a faixa etária entre 18 e 25 anos e $40 \%$ entre 26 e 40 anos. Somente $30 \%$ dos julgadores declarou gostar de "leite" de soja em um grau entre "ligeiramente" e "muitíssimo". A mesma porcentagem afirma consumir mensalmente tofu, proteína e/ou "leite" de soja, sendo que este produto é consumido semanalmente por somente $8 \%$ dos entrevistados.

Da Silva et al. (2007) avaliaram quatro bebidas com extrato hidrossolúvel de soja, em duas cidades brasileiras, sendo que $25 \%$ dos cariocas participantes e $26 \%$ dos londrinenses frequentemente consumiam soja. Em relação ao extrato de soja sabor natural, $40 \%$ dos cariocas e $45 \%$ dos londrinenses afirmaram gostar do produto. Referente à faixa etária, $27 \%$ dos cariocas tinham entre 40 e 50 anos, e $30 \%$ dos londrinenses tinham entre 30 e 40 anos. Através da pesquisa realizada, os autores perceberam que os provadores desgostaram ligeiramente de três das quatro amostras testadas, incluindo dois "leites" de soja comerciais. 


\section{CONCLUSÃO}

Através da caracterização físico-química das polpas, percebeu-se que a polpa de pitanga apresentou o maior teor de proteínas e de glicose, enquanto que a polpa de amora destacouse pelo teor de lipídios, umidade, acidez titulável total e $\mathrm{pH}$. Entretanto o maior conteúdo mineral foi observado na polpa de mirtilo que também demonstrou possuir maior quantidade de sólidos (solúveis, insolúveis e totais). A bebida de pitanga se destacou pelos maiores valores de $\mathrm{pH}$, cinzas, sólidos insolúveis totais e sólidos totais. Contudo, a acidez titulável total, as proteínas e os glicídios totais em glicose foram mais acentuados na bebida de amora. A bebida de mirtilo deteve os maiores teores de umidade, sólidos solúveis totais e lipídios.

As bebidas demonstraram possuir teor de proteínas dentro da faixa de produtos similares comercializados nacionalmente.

Aanálise sensorial apontou para boa aceitação das bebidas preparadas, com notas próximas a sete para o atributo impressão global, indicando que os provadores gostaram regularmente dos produtos testados.

Logo, a utilização das polpas de pitanga, amora e mirtilo na indústria são promissoras no desenvolvimento e/ou aprimoramento de novos produtos, como bebidas, contento extrato hidrossolúvel de soja, promovendo maior consumo deste tipo de alimento.

\section{ABSTRACT \\ PREPARATION AND CHARACTERIZATION OF SOYBEAN WATER EXTRACT JUICES WITH PITANGA, BLACKBERRY AND BLUEBERRY PULPS}

Currently, there is a consumer search for foods with high nutritional and functional properties, attracting the interest of agribusiness by fruits with exotic features. This work aims to develop soy-based juices in pitanga, blackberry and blueberry flavors. The pulps and drink characterization was performed through physico-chemical and microbiological analysis, besides the application of sensory analysis in the developed products. Among the physico-chemical analysis of mineral, protein, solids, lipids and carbohydrates content, the $\mathrm{pH}$ was the descriptor that best explained the difference between pulps and juices (Principal Component Analysis - PCA). In the juices' sensory analysis, the acceptance rate was satisfactory, indicating a potential for their industrialization and the need for aroma and flavor greater intensification in the finished product development.

KEY WORDS: FRUIT PULPS, ARAUCARIA FOREST, PHYSICO-CHEMICAL AND MICROBIOLOGICAL CHARACTERIZATION, SENSORY ANALYSIS.

\section{REFERÊNCIAS}

1 ABREU, C. R. A. de.; PINHEIRO, A. N.; MAIA, G. A.; CARVALHO, J. M. de; SOUSA, P. H. M. de et al. Avaliação química e físico-química de bebidas de soja com frutas tropicais. Alimentos e Nutrição, v. 18, n. 3, p. 291-296, set. 2007.

2 AGUIAR, I. B.; MIRANDA, N. G. M.; GOMES, F. S.; SANTOS, M. C. S.; REITAS, D. de G. C.; TONON, R. V.; CABRAL, L. M. C. Physicochemical and sensory properties of apple juice concentrated by reverse osmosis and osmotic evaporation. Innovative Food Science and Emerging Technologies, v. 16, p. 137-142, out. 2012.

3 ANTONIO, G. C.; FARIA, F. R.; TAKEITI, C. Y.; PARK, K. J. Rheological behavior of blueberry. Ciência e Tecnologia de Alimentos, v. 29, n. 4, p. 732-737, out./dez. 2009.

4 AROUCHA, E. M. M.; SOUZA, C. S. M. de; SOUZA, A. E. D. de; FERREIRA, R. M.de A.; FILHO, J. C. A. Qualidade póscolheita da cajarana em diferentes estádios de maturação durante armazenamento refrigerado. Revista Brasileira de Fruticultura, v. 34, n. 2, p. 391-399, jun. 2012. 
5 ABNT - Associação Brasileira de Normas Técnicas. NBR 14141. Escalas utilizadas em análise sensorial de alimentos e bebidas. Rio de Janeiro: ABNT, 1998.

6 BEHRENS, J. H.; DA SILVA, M. A. A. P. Atitude do consumidor em relação à soja e produtos derivados. Ciência e Tecnologia de Alimentos, v. 24, n. 3, p. 431-439, jul./set. 2004.

7 BEZERRA, C. V.; SILVA, L. H. M. da.; COSTA, R. D. S. da.; MATTIETTO, R. de A.; ROgRigueS, A. M. da C. Comportamento reológico de suco misto elaborado com frutas tropicais. Brazilian Journal of Food Technology, v. 16, n. 2, p. 155-162, abr./jun. 2013.

8 BICUDO, M. O. P.; VASQUES, E. de C.; ZUIM, D. R.; CANDIDO, L. M. B. Elaboração e caracterização de bebida fermentada à base de extrato hidrossolúvel de quinoa com polpa de frutas. Boletim do Centro de Pesquisa de Processamento de Alimentos, v. 30, n. 1, p. 19-26, jan./jun. 2012.

9 BRANCO, I. G.; TEIXEIRA, A. M.; RIGO, M.; BEZERRA, J. R. M. V.; COUTINHO, M. R.; ARGANDOÑA, E. J. S.; BASTOS, T. G. Avaliação da aceitabilidade sensorial de uma bebida à base de extrato hidrossolúvel de soja, polpa de morango e sacarose. Revista Ciências Exatas e Naturais, v. 9, n. 1, p. 129-141, jan./jun. 2007.

10 BRASIL. Ministério da Agricultura e do Abastecimento. Instrução Normativa nº1, de 07 de janeiro de 2000. Aprova o regulamento técnico geral para fixação dos padrões de identidade e qualidade para polpa de fruta. Diário Oficial da União, Brasília, 10 de janeiro de 2000, nº 6, seção 1, p. 54-58.

11 BRASIL. Ministério da Agricultura, Pecuária e Abastecimento. Instrução Normativa nº 62, de 26 de agosto de 2003. Oficializa os métodos analíticos oficiais para análises microbiológicas para controle de produtos de origem animal e água. Diário Oficial da União, Brasília, 18 de setembro de 2003, seção 1, p. 14.

12 BRASIL. Ministério da Saúde. Agência Nacional de Vigilância Sanitária. Resolução RDC nº 12, de 02 de janeiro de 2001. Regulamento técnico sobre padrões microbiológicos para alimentos. Diário Oficial da União, Brasília, 10 de janeiro de $2001, n^{\circ} 7$, seção 1 , p. 45-53.

13 CAUS, S.; CZAIKOSKI, C.; GOMES, G. V. de L.; CÓRDOVA, K. R. V.; BEZERRA, J. R. M. V. B. Obtenção de bebidas a base de extrato hidrossolúvel de soja com polpa de frutas. Revista Ciências Exatas e Naturais, v. 10, n. 1, jan./jun. 2008.

14 CELLI, G. B.; PEREIRA-NETTO, A. B.; BETA, T. Comparative analysis of total phenolic content, antioxidant activity, and flavonoids profile of fruits from two varieties of Brazilian cherry (Eugenia uniflora L.) throughout the fruit development stages. Food Research International, v. 44, p. 2442-2451, out. 2011.

15 CONAB - Companhia Nacional de Abastecimento. Acompanhamento de safra brasileira: grãos, décimo levantamento, julho 2013. Brasília: Conab, 2013. Disponível em: <http://www.conab.gov.br/OlalaCMS/uploads/ arquivos/13_07_09_09_04_53_boletim_graos_junho_2013.pdf $>$. Acesso em 02/10/2013.

16 DA SILVA, J. B.; PRUDÊNCIO, S. H.; FELBERG, I.; DELIZA, R.; CARRÃO-PANIZZI, M. C. Aceitabilidade de bebidas preparadas a partir de diferentes extratos hidrossolúveis de soja. Pesquisa Agropecuária Brasileira, v. 42, n. 12, p. 1779-1784, dez. 2007.

17 DUTCOSKY, S. D. Análise sensorial de alimentos. Curitiba: Champagnat, 2007. 239 p.

18 ERCISLI, S.; ORHAN, E. Chemical composition of white (Morus alba), red (Morus rubra) and black (Morus nigra) mulberry fruits. Food Chemistry, v. 103, p. 1380-1384, cv2007.

19 ERCISLI, S.; ORHAN, E. Some physico-chemical characteristics of black mulberry (Morus nigra L.) genotypes from Northeast Anatolia region of Turkey. Scientia Horticulturae, v. 116, p. 41-46, mar. 2008.

20 FACHINELLO, J. C. Mirtilo. Revista Brasileira de Fruticultura, v. 30, n. 2, p. 285-576, jun. 2008.

21 FELBERG, I; DELIZA, R.; GONÇALVES, E. B.; ANTONIASSI, R.; FREITAS, S. C. de; CABRAL, L. C. Bebida mista de extrato de soja integral e castanha-do-Brasil: caracterização físico-química, nutricional e aceitabilidade do consumidor. Alimentos e Nutrição, v. 15, n.2, p. 163-174, 2004.

22 IMRAN, M.; KHSN, H.; SHAH, M.; KHARAN R.; KHAN, F. Chemical composition and antioxidant activity of certain Morus species. J Zhejiang Univ-Sci B (Biomed \& Biotechnol), v. 11, n. 12, p. 973-980, dez. 2010.

23 ISO - International Organization for Standardization. Microbiology of food and animal feeding stuffs - horizontal method for the enumeration of presumptive Bacillus cereus - colony-count technique at $30{ }^{\circ} \mathrm{C}$. DS/EN ISO 7932. $17 / 02 / 2005$.

24 LOPES, A. S.; MATTIETTO, R. de A.; MENEZES, H. C. de. Estabilidade da polpa de pitanga sob congelamento. Ciência e Tecnologia de Alimentos, v. 25, n. 3, p. 553-559, jul./set. 2005.

25 MEDEIROS, J. F. de.; AROUCHA, E. M. M.; DUTRA, I.; CHAVES, S. W. P.; SOUZA, M. S. de. Efeito da lâmina de irrigação na conservação pós-colheita de melão Pele de Sapo. Horticultura Brasileira, v. 30, n. 3, p. 514-519, jul./set. 2012. 
microbiota, colour, bioactive compounds and antioxidant activity of pasteurised pomegranate juice. Food Chemistry, v. 141, p. 2122-2129, dez. 2013.

27 MERCALI, G. D.; SAKIRS, J. R.; JAESCHKE, D. P.; TESSARO, I. C.; MARCZAK, L. D. F. Physical properties of acerola and blueberry pulps. Journal of Food Engineering, v. 106, p. 283-289, out. 2011.

28 MESQUITA, K. S.; MARTINS, G. A. de S.; CALHEIROS, C. A.; BORGES, S. V.; CARNEIRO, J. de D. de S.; FERRUA, F. Q. Elaboração, caracterização química e avaliação sensorial de néctares de bananas das variedades prata, nanica e marmelo. Alimentos e Nutrição, v. 20, n. 3, p. 451-455, jul./set. 2009.

29 MORAES, J. O. de.; PETUZATTI. P. B.; CORRÊA, F. V.; SALAS-MELLADO, M. de Las M. Estudo do mirtilo (Vaccinium ashei Reade) no processamento de produtos alimentícios. Ciência e Tecnologia de Alimentos, v. 27 (suppl.), p. 18-22, ago. 2007.

30 MORAIS, A. A. C.; SILVA, A. L.; DAMÁSIO, A. B. F. Otimização do uso da soja. Revista Brasileira de Nutrição Clínica, v. 15 , n. 2, p. 350-357, abr./jun. 2000.

31 MOTA, R. V. da. Caracterização do suco de amora-preta elaborado em extrator caseiro. Ciência e Tecnologia de Alimentos, v. 26, n. 2, p. 303-308, abr./jun. 2006.

32 OLIVEIRA, A. L.; LOPES, R. B.; CABRAL, F. A.; EBERLIN, M. N. Volatile compounds from pitanga fruit (Eugenia uniflora L.). Food Chemistry, v. 99, n. 1, p. 1-5, 2006.

33 OLIVEIRA, D. M.; MARQUES, D. R.; KWIATKOWSKI, A.; MONTEIRO, A. R. G.; CLEMENTE, E. Sensory analysis and chemical characterization of cereal enriched

34 with grape peel and seed flour. Acta Scientiarum. Technology, v. 35, n. 3, p. 427-431, jul./set. 2013.

35 OLIVEIRA, F., N. de; FIGUEIRÊDO, R. M. F. de; QUEIROZ, A. J. de M. Análise comparativa de polpas de pitanga integral, formula e em pó. Revista Brasileira de Produtos Agroindustriais, v. 8, n. 1, p. 25-33, 2006.

36 OZRENK, K.; GAZIOGLU S. R. I.; ERDINC C.; GULERYUZ, M.; AYKANAT, A. Molecular characterization of mulberry germplasm from Easter Anatolia. African Journal of Biotechnology, v. 9, n. 1, p. 001-006, jan. 2010.

37 PINHEIRO, A. M., FERNANDES, A. G.; FAI, A. E. C., PRADO, G. do; SOUSA, P. H. M. de; MAIA, G. A. Avaliação química, físico-química e microbiológica de sucos de frutas integrais: abacaxi, caju e maracujá. Ciência e Tecnologia de Alimentos, v. 26, n. 1, p. 98-103, jan./mar. 2006.

38 POlYCARPO, G. do V.; SILVA, A. A. R. da; FRUCHI, V. M.; RIGOBELO, E. C.; CRUZ, V. C. da; NICODEMO, D. Enriquecimento da dieta do bicho-da-seda com extrato hidrossolúvel de soja. Ciência Rural, v. 42, n.9, p. 1669-1674, set. 2012

39 RIBEIRO, E. P.; SERAVALLI, E. A. G. Química de alimentos. São Paulo: Blucher, 2007. 196 p.

40 RIVALDI, J. D.; SILVA, M. M.; COELHO, T. C.; OLIVEIRA, C. T. de; MANCILHA, I. M. de. Caracterização e perfil sensorial de hydromel produzido por Saccharomyces cerevisiae IZ 888. Brazilian Journal of Food Technology, VII BMCFB, jun. 2009.

41 RODRIGUES, R. da S.; MORETTI, R. H. Caracterização físico-química de bebida protéica elaborada com extrato de soja e polpa de pêssegos. Boletim do Centro de Pesquisa de Processamento de Alimentos, v. 26, n. 1, p. 101-110, jan./jun. 2008.

42 RODRÍGUEZ-ROQUE, M. J.; ROJAS-GRAÜ, M. A.; ELEZ-MARTÍNEZ, P.; MARTÍN-BELLOSO, O. Soymilk phenolic compounds, isoflavones and antioxidant activity as affected by in vritro gastrointestinal digestion. Food Chemistry, v. 136, p. 206-212, jan. 2013.

43 SANTOS, M. da S.; PETKOWICZ, C. L. de O.; WOSIACKI, G.; NOGUEIRA, A.; CARNEIRO, E. B. B. Caracterização do suco de araçá vermelho (Psidium cattleianum Sabine) extraído mecanicamente e tratado enzimaticamente. Acta Scientiarum Agronomy, v. 29, supl., p. 617-621, 2007.

44 SARKIS, J. R.; JAESCHKE, D. P.; TESSARO, I. C.; MARCZAK, L. D. F. Effects of ohmic and conventional heating on anthocyanin degradation during the processing of blueberry pulp. LWT - Food Science and Technology, v. 51, p. 7985, abr. 2013.

45 SEAB - Secretaria de Estado da Agricultura e do Abastecimento. Fruticultura - Análise da Conjuntura Agropecuária. Dezembro de 2012. Disponível em: <http://www.agricultura.pr.gov.br/arquivos/File/deral/Prognosticos/ fruticultura_2012_13.pdf>. Acesso em: 28/10/2013.

46 SILVA, R. do N.; MONTEIRO, V. N.; ALCANFOR, J. D. X.; ASSIS, E. M.; ASQUIERI, E. R. Comparação de métodos para a determinação de açúcares redutores e totais em mel. Ciência e Tecnologia de Alimentos, v. 23, n. 3, p. 337-341, set./dez. 2003.

47 SOUZA, G. C.; CARNEIRO, J. G.; GONSALVES, H. R. de O. Qualidade microbiológica de polpas de frutas congeladas produzidas no município de Russas-CE. ACSA - Agropecuária Científica no Semi-Árido, v. 7, n. 3, p. 01-05, jul./set. 2011. 
48 ULIANA, M. R.; VENTURINI FILHO, W. G. Análise energética de bebida mista de extrato hidrossolúvel de soja e suco de amora. Botucatu, v. 25, n. 3, p. 94-103, 2010.

49 VIEIRA, S. M.; SILVA, T. M.; GLÓRIA, M. B. A. Influence of processing on the levels of amines and proline and on the physico-chemical characteristics of concentrated orange juice. Food Chemistry, v. 119, p. 7-11, mar. 2010.

50 ZENEBON, O.; PASCUET, N. S.; TIGLEA, P. (Coord.). Métodos físico-químicos para análise de alimentos. São Paulo: Instituto Adolfo Lutz, 2008. 1020 p. 